\title{
Binding Study of Naringenin Derivatives and Cyclin Dependent Kinase 2
}

\author{
Hojung Kim, Eunjung Lec, Jihye Kim, Jinyoung Kim, Haeyoung Lim, \\ Chul-Hoon Lec, ${ }^{\dagger}$ Joong-Hoon Ahn, Youhoon Chong, and Yoongho Lim ${ }^{*}$
Bio/Molectar Informaics Center, Department of Bioscience and Biotechnology, Konkuk Liniversity, Seoul 173-701, Korea
E-mail: yoongho'àkonkuk.ac,kr Received March 23, 2007 \\ "Department of Medical Genetics \& Institute of Biomedical Science, College of Medicine, Hanvang University. Seoul 133-791. Korea
}

Key Words : Cyclin dependent kinase 2, Naringenin. NMR, in silico

It has been reported that antioxidant activities of herbs are caused by phenolic compounds, which can be classified based on their carbon skeletons.' Among several classes of phenolic compounds, a group with the core structure of C6C3-C6 is named flavonoids (benzo- $\gamma$-pyran derivatives). consisting of phenolic and pyran rings. According to the oxidation state of pyran ring. flavonoids can be further subdivided into five major subclasses as follows: flavonols. flavanols, flavones, isoflavones, and anthocyanidins. ${ }^{2}$ These structures can be varied by methylation, hydrogenation. hydroxylation, glycosylation, and so on. Flavonoids show many biological activities including apoptotic effects. Since apoptosis is one of the methods to control tumor formation. compounds inducing apoptosis can be considered as antitumor agents. On the other hand, cyclin dependent kinases. one of SeriThr kinase family, play important roles in cell cycle. Among them, cyclin dependent kinase 2 (CDK2) is participated in transition of $\mathrm{G} 1 / \mathrm{S}$ phase and progression of $\mathrm{S}$ phase. ${ }^{4}$ Importantly, inhibition of CDK2 induces apoptosis. ${ }^{5}$ Therefore, it can be helpful for us to measure binding affinity between $\mathrm{CDK} 2$ and its ligand.

First, in silico experiment was carried out before preparing CDK2 protein sample. Because it was known that one of flavanones, naringenin induces apoptosis in HeLa cell line. its derivatives were tested for binding with CDK2. The three dimensional (3D) structures of CDK2 and naringenin were IAQI.pdb and 1CGK.pdb, respectively, by X-ray crystallography.

Because naringenin has solubility problem in aqueous solution, the derivatives were designed to increase their hydrophilicity. As a result, 7-hydroxyl group of naringenin was substituted with amino acids and glucose. Five naringenin (1) derivatives were selected in this experiment as follows: 5-hydroxy-2-(4-hydroxyphenyl)-4-oxochroman-7yl alanine (2), 5-hydroxy-2-(4-hydroxyphenyl)-4-oxochroman-7-yl valine (3), 5-hydroxy-2-(4-hydroxyphenyl)-4oxochroman-7-yl methionine (4). 5-hydroxy-2-(4-hydroxyphenyl)-4-oxochroman-7-yl phenylalanine (5), and 5hydroxy-2-(4-hydroxyphenyl)-4-oxochroman-7-yl glucose (6) (Fig. 1).

When naringenin derivatives are docked into CDK2 using FlexX (Tripos, St.Louis, MO, USA), four derivatives except derivative 6 are bound to the protein well. As shown in

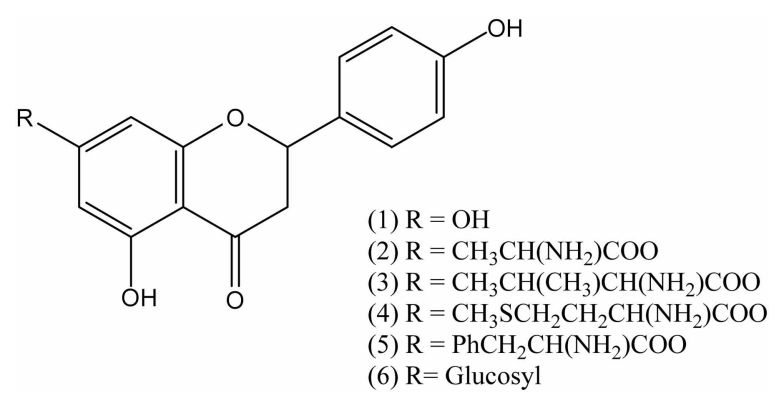

Figure 1. Structures of naringenin and its derivatives. 1: naringenin; 2: 5-hydroxy-2-(4-hydroxyphenyl)-4-oxochroman-7-y alanine: 3: 5-hydroxy-2-(4-hydroxyphenyl)-4-oxochroman-7-yl valine: 4: 5-hydroxy-2-(4-hydroxyphenyl)-4-oxochroman-7-yl methionine: 5: 5-hydroxy-2-(4-hydroxyphenyl)-4-oxochroman-7-yl phenylalanine: 6: 5-hydroy-2-(4-hydroxy phenyl)-4-oxochroman$7-y \mid$ glucose.

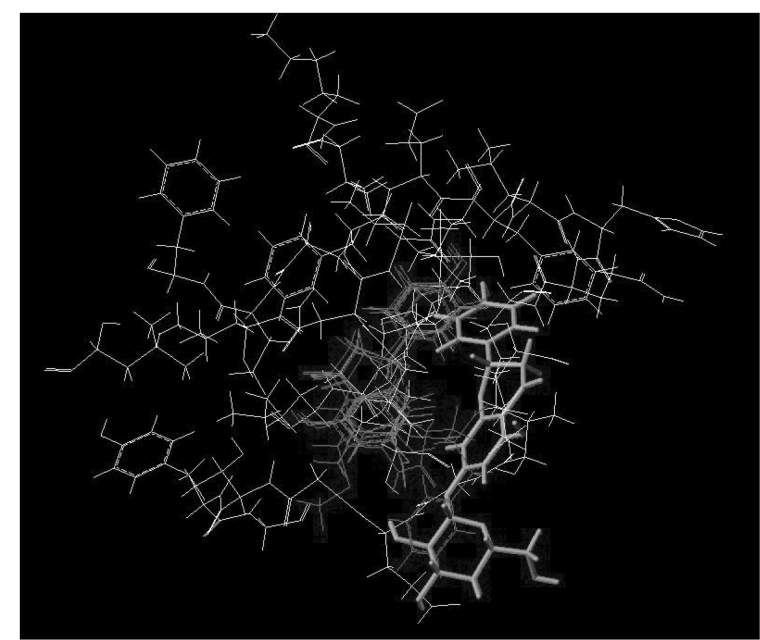

Figure 2. While five derivatives $\mathbf{1 - 5}$ (magenta color) are bound to the binding site of (IBK2 (white color), derivative 6 (cyan color) is placed out of the binding site.

Figure 2, it is easy to evaluate whether the ligand is docked into the protein or not. In the case of derivative 6 , it cannot enter into $\mathrm{CDK} 2$ and stays just outside the protein.

To prove the result obtained from in silico experiments, NMR spectroscopy was applied. A large molecule such as protein has a faster relaxation rate in solution and a slower 
diffusion rate than a small molecule such as a ligand. Therefore, the NMR signal of the protein is broaden by fast relaxation. While a ligand results in sharp NMR signal, the complex of a ligand and a protein makes a broad NMR signal. As a result, the change of NMR signals of a ligand can provide information about a formation of the complex. First of all. CDK2 protein was prepared to carry out NMR experiment

The open reading frame of human CDK2 (GenBank accession number X61622) was subcloned into pGEX 5X-1 $E$. coll expression vector. In order to express the recombinant CDK2, the transformant was grown in LB medium containing $50 \mu \mathrm{g} / \mathrm{ml}$. ampicillin. The culture grew until absorbance at $600 \mathrm{~nm}$ reached 0.7 . At this point, isopropyl$\beta$-D-thiogalactoside (IPTG) was added at a final concentration of $0.1 \mathrm{mM}$, and the transformant was grown for $5 \mathrm{hrs}$ at $28^{\circ} \mathrm{C}$. The cell was harvested, resuspended in phosphate buffered saline (PBS) buffer ( $10 \mathrm{mM} \mathrm{NaH} \mathrm{PO}_{4}, 150 \mathrm{mM}$ $\mathrm{NaCl}, \mathrm{pH} 7.2$ ), and lysed by sonication. The expressed protein was purified with GSIrap affinity column (Amersham Biosciences, Piscataway, NJ, USA). The protein was collected in GST elution buffer $(10 \mathrm{mM}$ glutathione, $50 \mathrm{mM}$ Tris$\mathrm{HCl}$ at $\mathrm{pH} 8.0,10 \%$ glycerol in $\mathrm{D}_{2} \mathrm{O}$ solvent), and concentrated using centricon (Millipore Corporation, Bedford, MA, $\mathrm{USA}_{4}>10 \mathrm{kDa}$ ). Naringenin derivatives were dissolved in a mixture of GSI elution buffer in $\mathrm{D}_{2} \mathrm{O}$ and $0.1 \% \mathrm{DMSO} \mathrm{d}_{6}$. Their final concentrations were adjusted to $100 \mu \mathrm{M}$.

The ${ }^{1} \mathrm{H}$ NMR data of naringenin derivatives alone without CDK2 were collected. Twenty $\mu \mathrm{l}$. of $\mathrm{CDK} 2$ was added into the NMR tube containing the derivatives, and their NMR data were collected. Five repeated additions of CDK2 solution were carried out. When buffer solution alone was added into the NMR tube containing naringenin derivatives, as shown in Fig. 3A, the NMR signals were not changed. On the other hand, in the case of derivative 2 , an increment of CDK2 addition showed drastic changes of the 'H NMR signals between $6 \mathrm{ppm}$ and $7.5 \mathrm{ppm}$ ( $\mathrm{Fig}$. 3B). Like derivative 2, derivatives $\mathbf{4}$ and $\mathbf{5}$ showed decreases of the proton signals. However, in the case of derivative 6, CDK2 addition resulted in small changes of the proton signals as shown in Figure $3 \mathrm{C}$. In addition. the NMR change pattern of derivative 3 was the same as that of the derivative 6 .

Results obtained from in silico experiments are consistent
(A)

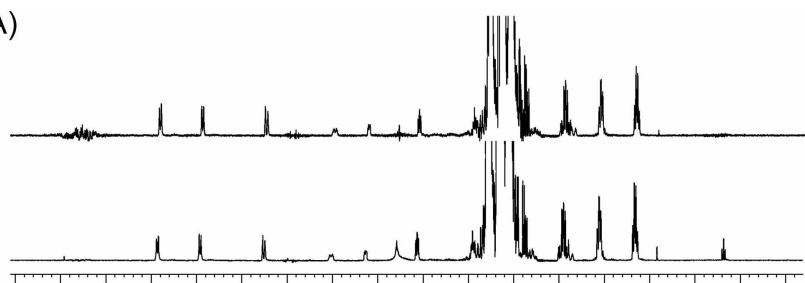

(B)

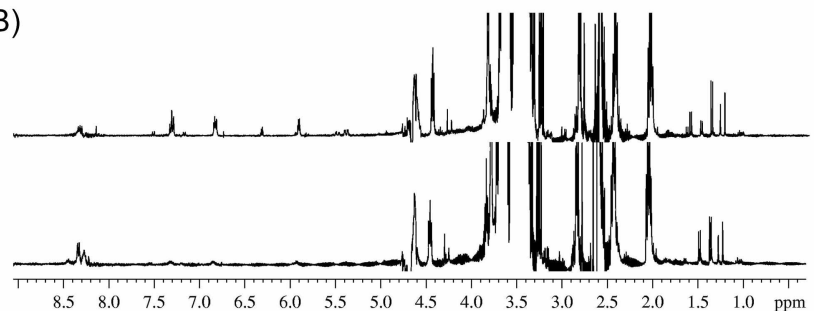

(C)

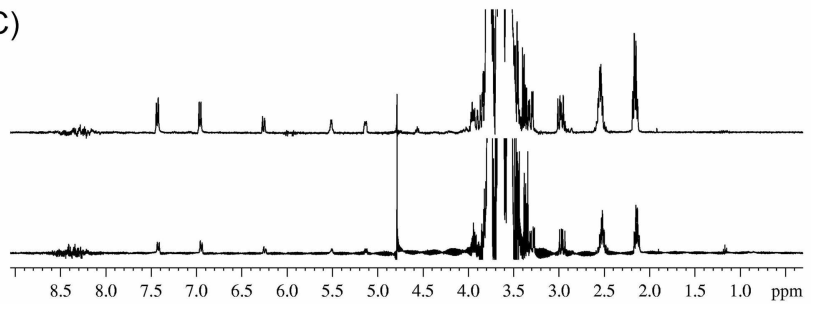

Figure 3. (A) The addition of bufler solution alone into the NMR tube containing derivative 2 . (B) The addition of wach $20, t \mathrm{~L}$ of CDK2 solution into the NMR tube containing derivative 2 . (C) The addition of each $20 \mu \mathrm{l}$. of CIOK2 solution into the NMR tube containing derivalive 6.

with the observation obtained from the binding assay using the NMR spectroscopy except derivative 3. It was not carried out here to determine binding affinity quantitatively between CDK2 and naringenin derivatives from in silico docking, so that the binding affinities among derivatives $2-5$ with CDK2 could not be distinguished quantitatively. In order to explain the inconsistency of derivative 3, further experiments in cellular level are remained for the future study.

\section{Experimental Section}

The 3D structures of naringenin derivatives were built up using Sybyl 7.1 (Tripos, St.Louis, MO. USA) on a Pentium<smiles>O=C1CC(c2ccc(O)cc2)Oc2cc(O)cc(O)c21</smiles>

1<smiles>[2H]C(NC(=O)OCc1ccccc1)C(=O)O</smiles>

7
1. $\mathrm{EDCl}, \mathrm{CH}_{2} \mathrm{Cl}_{2}, \mathrm{rt}$

2. TFA, $\mathrm{CHCl}_{3}, 0^{\circ} \mathrm{C}$<smiles>[R]C(N)C(=O)Oc1cc(O)c2c(c1)OC(c1ccc(O)cc1)CC2=O</smiles>

8

$$
\begin{array}{ll}
\text { 7a } & \mathrm{R}=\mathrm{CH}_{3} \\
\text { 7b } & \mathrm{CH}\left(\mathrm{CH}_{3}\right)_{2} \\
7 c & \mathrm{CH}_{2} \mathrm{CH}_{2} \mathrm{SCH}_{3} \\
7 d & \mathrm{CH}_{2} \mathrm{Ph}
\end{array}
$$$$
2 \mathrm{R}=\mathrm{CH}_{3}
$$$$
3 \quad \mathrm{CH}\left(\mathrm{CH}_{3}\right)_{2}
$$$$
4 \quad \mathrm{CH}_{2} \mathrm{CH}_{2} \mathrm{SCH}_{3}
$$$$
5 \quad \mathrm{CH}_{2} \mathrm{Ph}
$$

Scheme 1. Synthesis ol naringenin-amino acid ester (8) from naringenin (1). 
IV $3.2 \mathrm{GHz}$ Linux PC. The derivatives were subjected to energy minimization. Conjugate gradients were carried out until maximun derivative of $0.5 \mathrm{kcal} / \mathrm{mol} \hat{\AA}$ for maximum iteration of 1.000 with Gasteiger-Huckel charge, and the forcefield was Tripos standard forcefield. The derivatives were docked onto CDK2 protein using FlexX module (Tripos) on a Pentium IV $3.2 \mathrm{GHz}$ Linux PC. The binding site for docking included residues as follows: I10-G11-EI2G13-T14-Y15-Gl6-VI8-V30-A31-L32-K33-V64-K65-L78F80-E81-F82-L83-H84-Q85-D86-K88-P130-Q131-N132L133-Ll34-Al 4+-Dl45-Fl46-LI48

All derivatives except 5-hydrosy-2-(4-hydrosyphenyl)-4oxochroman-7-yl glucose (6) were synthesized. Naringenin and 5-hydroxy-2-(4-hydroxyphenyl)-4-oxochroman-7-yl glucose were purchased from INDOFINE chemical company. Inc. (Hillsborough. NJ, USA). Synthetic procedures are shown in Scheme 1. Due to the possible epimerization at $\alpha$ carbon of the amino acid. we decided to use EDCI-promoted peptide coupling conditions. The reaction was sensitive to the solvent presumably due to the poor solubility of naringenin, and after extensive survey of the appropriate solvent system for the coupling reaction, methylene chloride $\left(\mathrm{CH}_{2} \mathrm{Cl}_{2}\right)$ was found to be the best choice for solvent. Thus. a mixture of naringenin and $\mathrm{N}$-protected amino acid in anhydrous $\mathrm{CH}_{2} \mathrm{Cl}_{2}$ was treated with l-ethyl-3-(3-dimethylaninopropyl)carbidiimide hydrochloride at room temperature. The initial slurry became a clear solution as the reaction proceeded. and was completed in $2-5$ lirs. Because the naringenin-amino acid adduct was easily decomposed by hydrolysis in the basic conditions, the coupling reaction was performed without base. Thus, $N$-Boc-alanine (7a) was condensed with naringenin (1), which was immediately treated with trifluoroacetic acid in $\mathrm{CHCl}_{3}$ followed by trituration with diethyl ether to give free naringenin-L-alanine ester (2) in good yield ( $65 \%$. Scheme 1). Regioselectivity of the coupling reaction was confirmed by nuclear Overhauser effect (NOE) contacts between $\mathrm{H} 6 / \mathrm{H} 8$ (6.04 and $6.02 \mathrm{ppms}$ ) and $\mathrm{Ha}$ of alanine $(3.95 \mathrm{ppm})$ of the final compound $8 \mathrm{a}$. The funal compound. 8a was pure enough for the alcoholysis of the ester after trituation with ether, to produce naringenin and amino acid ester. Other naringenin derivatives 3-5 were obtained by using the same reaction conditions as explained above with $60-70 \%$ yield. Spectral data of all synthetic derivatives and their synthetic methods in detail were reported previously. ${ }^{6}$

All NMR measurements were performed on a Bruker Avance 400 spectrometer system ( 9.4 T, Karlsruhe. Gemany) at $298 \mathrm{~K}$. The ${ }^{1} \mathrm{H}$ NMR data were collected in GST elution $\mathrm{D}_{2} \mathrm{O}$ buffer solution. Two hundred and fifty six transients were acquired with a $1 \mathrm{~s}$ relaxation delay, using $32 \mathrm{~K}$ data points. The $90^{\circ}$ pulse duration was $10.2 \mu$ s and the spectral width was $5,000 \mathrm{~Hz}^{7.8}$

Acknowledgments. This work was supported by grant KRF-2006-005-J03402 (KRF). grant R01-2004-000-106880 (KOSEF), Biogreen 21 (Korea Ministry of Agriculture and Forestry), and grant from the second BK2L (MOE). Hojung Kim and Eunjung Lee contributed equally to this work.

\section{References}

1. Skerget. M: Kotnik. P: Hadolin. M: Hras, A. R; Simonic. M: Knez. Z. Food Chent 2005. 89. 191-198.

2. Cook. N. C.: Samman. S. Nutt Biochent 1996. 7. 66-76.

3. Mani. S.: Wang. C.: Wu. K.: Francis. R.: Pestell. R. Expert. Opin. Investig. Drugs 2000, 9, 1849-1870.

4. Datta. N. S: Williams. J. L.; Long. M. W. Cell Growth Diffe. 1998. $9.639-650$

5. Payton. M.: Chung. G: Yakowec. P: Wong. A.: Powers. D: Xiong. L.: Zhang. N.: Leal. T.: Bush. T. L.: Santora. V: Askew. B.: Tasker. A.: Radinsky. R.: Kendall. R.: Coats. S. Cancer Res 2006. 66. $4299-4308$

6. Kim. J.; Lee. Y.: Kim, H.: Kang. S.; Park. K: Cho, J.: Lee, Y: Kim. B.: Lim. Y; Chong. Y. Bull. Korean Chem. Soc. 2005. 26. 2065-2068

7. Park. Y. H.: Lee. Y. U.: Kim. H. I.: Lee. Y. S.: Yoon. Y. D.: Moon1. B. H.: Chong. Y. H.: Ahn. J. H.: Shim. Y. H.: Lim. Y. H. Bull. Korean Chem. Soc. 2006. 27, 1537-1541

8. Yang. H. J.: Lim. Y. H. Bull. Korean Chem. Soc 2005. 26, 845848 